\title{
The New Neuroanatomy of the Spinal Cord *
}

\author{
J. T. Hughes, MD, DPhil, FRCP \\ Department of Neuropathology, Radcliffe Infirmary, Oxford, UK.
}

\section{Summary}

In the last 2 decades, the application of new techniques in neuroanatomy has led to spectacular advances in our knowledge of the structure and function of the human spinal cord. In 1988, it is appropriate to review this progress, and I am grateful to Sir George Bedbrook and the organisers of the International Paraplegia Meeting in Perth, Western Australia, for inviting me to give this survey, to which I have given the title 'The New Neuroanatomy of the Spinal Cord'.

\section{Classical neuroanatomy}

In the nineteenth century, techniques of anatomical study, using histological sections with specific staining of nerve cells and their processes, began drawing the picture of the spinal cord that now appears in our modern textbooks. Many observers in the subject of human anatomy contributed to this work. Purkinje (1787-1869) used the microtome to cut and stain sections from embedded tissues of the central nervous system. Deiters (1834-1863) first recognised and described the basic structure of the nerve cell with its axon and dendrites. Burdach (1776-1847), when he described the cuneate fasciculi, made an important first step in understanding the anatomy of white matter tracts, a subject taken further by Kolliker (1817-1905) who described different types of nerve cells, and followed the axons of some to their termination. These workers lacked the specific histological techniques in neuroanatomy, the emergence of which was the next important step in the subject.

Marchi (1851-1908) developed his method with osmic acid of staining degenerating myelin, thus revealing tract degenerations in the central nervous system, either as a consequence of human disease and trauma, or after specific lesions created in animal experiments. The Marchi technique enabled white matter tracts to be followed from their origin to their termination. Waller (1816-

* Invited lecture presented at the Annual Scientific Meeting of the International Medical Society of Paraplegia, Perth, Western Australia, May 1988. 
70) demonstrated the changes in the axon, myelin sheath and neurone cell body following axon section, an important tool in tracing severed tracts retrogradely to their cells of origin. Nissl (1860-1919) perfected a simple staining of the nerve cell using at first magenta red, and later, methylene blue.

Then appeared on the scene of neuroanatomy two giants of anatomical discovery, Golgi and Cajal, and both were to receive the Nobel prize in physiology and medicine, jointly in 1906. Golgi (1843-1926) developed his silver chromate method for staining nerve cells permitting for the first time a complete sight of the nerve cell, including its main axon, and all its dendritic processes. Cajal (1852-1934), refining the method of Golgi, which he encountered in 1887, used this method in a systematic study of the nervous system of man and vertebrate animals, to such effect that by the date of the publication of his historic textbook Textura del Sistema Nervioso del Hombre y de los Vetebrados (Ramon y Cajal, 1899-1904, he was famous throughout the scientific world, and 2 years later received the Nobel prize. It is a measure of the immense and farseeing work of this anatomical genius that the modern editions of the principal textbooks of Cajal (Ramon y Cajal, 1952; 1959) still provide an important reference source for the anatomy of the spinal cord and its reaction to trauma.

This type of anatomical work, using histological sections stained, with silver methods for axons, and with Weigert-Pal or Marchi techniques for myelin, continued into the twentieth century, and still has its use today. However, as the anatomical structure of the spinal cord was repeatedly observed, fewer new anatomical details were added, since the classical techniques of neuronal, axonal, and myelin staining of histological sections permitted of no great advancement of original observations.

\section{Neurophysiology}

Accompanying classical neuroanatomy came the great expansion of our knowledge of neurophysiology with studies in experimental animals of the neuronal function of the spinal cord. Bernard (1813-1878) in Paris, Muller, and Bois-Reymond in Berlin, and Ferrier (1843-1928) and Horsley (1857-1916) in London were notable pioneers in neurophysiology but the greatest advances came with the sustained work of Sherrington (1856-1952) in Liverpool and Oxford. For his researches on reflex action, which became widely known from his book 'The Integrative Action of the Nervous System' (Sherrington, 1906), he was, in 1932, awarded the Nobel prize. His pupils, and their successors throughout the world, developed a new science of neurophysiology, and added to our knowledge of the anatomy of the spinal cord, an understanding of its function and in particular its reflex activity.

In the last 30 years, we have seen the creation of the subject of clinical neurophysiology using electrophysiological techniques, based on Sherrington's methods for experimental animals, but applied to the study of the human nervous system in disease, and after various types of trauma. These observations are now providing an important body of information on the neurophysiology of the human spinal cord in normal individuals and in individuals suffering from trauma or disease affecting the spinal cord. They may be used, for example, to expand data from clinical neurological testing of complete and incomplete lesions of the spinal cord, and are particularly useful in monitoring progress. 


\section{The new neuroanatomy as revealed by neurochemistry}

In the last 10 years we have seen a further important development in techniques of examining the neuroanatomy of the human spinal cord. These methods, originally applied to experimental animals, are now being used in neuroanatomical observations on the human spinal cord from cadavers. The subject will be discussed under the following headings: the discovery, manufacture, and testing of monoclonal and polyclonal antibodies specific to neuropeptides; the 'classical' neurotransmitters discovered in early work on the subject; the 'new' neuropeptides identified mainly with monoclonal but also with polyclonal antibodies; our modern knowledge of spinal cord anatomy in the light of these discoveries.

\section{The discovery of monoclonal antibodies}

Whilst antibodies to various components of the central nervous system have been developed over several decades, the abundance of antibodies, each one specific to one special component of the nervous system, has come about from the creation of monoclonal antibodies by the hybridoma techniques, initiated by Kohler and Milstein (1975). The methods depend on the fusing of lymphoid cells derived from specifically immunised animals with the cells of a malignant myeloma. Usually, both the lymphoid cells and the myeloma cells are derived from mice. These fused cells, which combine the properties of a malignant tumour with those of a cell making a specific antibody, can be made to grow as tumours in the peritoneal cavity of the experimental animals. The mice with peritoneal tumours develop ascites and the peritoneal exudate is rich in the specific antibody required. The fused cells can also be made to replicate in tissue culture, and the specific antibody can be extracted from the nutrient fluid substrate of the culture. This brief description summarises how clones of cells from such hybridomas yield a specific antibody which, because it derives from a single line of cell division, is called a monoclonal antibody.

It was soon found that monoclonal antibodies could be produced against many important neural proteins. For example, a monoclonal antibody against serotonin (Consolazione, Milstein, Wright and Cuello, 1981) provided a new and precise method of examining serotonin in the body. Monoclonal antibodies have serveral important advantages over polyclonal antibodies. Because of their production from a single cell line, they are usually more specific, and can be used without the extensive absorption processes necessary to prepare and purify polyclonal antibodies. Although the original production and testing of a useful monoclonal antibody is capricious, difficult, and time consuming, the antibody can eventually be produced in great abundance, and, if the tumour strain in the animal or the line of cells in tissue culture line are carefully perpetuated, there is a permanent source of antibody. Using a marker, which may be a florescein label, visible with ultra violet light, or peroxidase seen as a yellowish brown pigment, the location and to some extent the concentration of the antigen, can be demonstrated in histological sections. Some monoclonal antibodies will perform their function only in frozen sections. Other antibodies, more frequently polyclonal antibodies, will react on sections cut from tissues embedded in paraffin blocks, sometimes even when the tissues have had prolonged fixation in 
formalin prior to embedding. In this way polyclonal antibodies, often produced in rabbits, usefully supplement monoclonal antibodies. We now have numerous monoclonal and polyclonal antibodies to various proteins in the central nervous system and in particular to many important neuropeptides.

\section{Classical neuropeptides}

Before considering the long list of neuropeptides now identified by means of specific antibodies, we must mention those known from earlier techniques of neurophysiology and neurochemistry. The first neurotransmitter to be identified in the spinal cord was acetylcholine, an excitatory substance, which is released at the terminations of the motoneurones in the anterior horn (See Eccles, 1957 for a summary of this and other early transmitters). Then came knowledge of noradrenaline and dopamine which are catecholamines, followed by the recognition of the monoamine, serotonin. Gamma-aminobutyric acid (GABA) and glycine are amino acids and inhibitory, whilst an excitatory neurotransmitter is glutamic acid. The seven substances described above are among those termed 'classical transmitters' (Cuello, Priestley and Soffroniew, 1983), being known from the earliest work on neuropeptides. Most have rather small molecules with a chemical structure which does not readily form antibodies. Antibodies have, however, been made against serotonin and dopamine, and may also be raised against the enzymes involved in their synthesis. The synthesising enzyme of a neurotransmitter will be a protein, and consequently antigenic, permitting the creation of a specific antibody, to be used, for example, in anatomical mapping of the distribution of the transmitter. In this way, antibodies to the enzymes choline acetyltransferase, glutamic acid decarboxylase (which converts glutamate to GABA), and tyrosine hydroxylase, may be used to study the anatomical localisation of acetylcholine, glutamic acid, GABA, and tyrosine.

We now come to the review of the more recently discovered neuropeptides in the spinal cord, a much more difficult area, because of the rapid additions to our knowledge of these substances. The peptides active in the spinal cord now number about 40, and of these 10 have been selected for discussion here, the choice being influenced by the extent of our knowledge, and to some extent by the author's personal acquaintance with the use of antibodies to these antigens in sections of the human spinal cord.

Substance P. Substance $\mathbf{P}$ was discovered in 1931 (Euler and Gaddum, 1931) as an active principle in certain tissue extracts, and later shown to have important functions in the brain (Pioro, Hughes and Cuello, 1984a) and spinal cord (Cuello, Polak and Pearse, 1976; Hunt, Rossor, Emson et al., 1982; Pioro, Hughes and Cuello, 1984b). In the spinal cord, it is known in the posterior horn as an important neurotransmitter in areas, such as the substantia gelatinosa, which receive nociceptive afferents. It is also found in the anterior horn (Cuello and Kanazawa, 1978) where it is closely associated with motoneurones and is related to the terminations of both the descending corticospinal fibres and fibres of intrinsic spinal neurones. More recently (Pioro, Hughes and Cuello, 1984) it has been shown to be present on terminations of the neurone cell bodies in the nucleus dorsalis in the human spinal cord. 
Enkephalin. Enkephalin is the name given to two pentapeptides resembling morphine in their actions on the nervous system (Hughes, 1975; Hughes, Smith, Kosterlitz et al., 1975; Hughes, Kosterlitz and Smith, 1977; La Motte and de Lanerolle, 1981; Schoenen, Lotstra, Vierendeels et al., 1985). It is known to occur in the human posterior horn, most abundantly in laminae II, and to be important as a neurotransmitter in the termination of afferents arriving from the posterior roots and ending in the posterior horns. It has also been regularly found in the anterior horn in the terminations of fibres in contact with motoneurones, including the neurones of the Nucleus of Onuf, and the autonomic neurones in the thoracic and sacral cord (Gibson, Polak, Katagiri et al., 1988).

Somatostatin. Somatostatin, also referred to as Growth Hormone Release-Inhibiting Hormone, is found throughout the brain and in many other organs such as pancreas and gastrointestinal tract (Brownstein, 1977). It is prominent in the posterior horn particularly in lamina II, and is known to be concerned with the innervation of pelvic organs (Schroeder, 1984).

Thyrotropin-releasing hormone. Thyrotropin-releasing hormone is now known in many areas of the brain outside the hypothalamus, where the highest concentrations are found. This hormone has now been discovered to have a very important effect on the upper and lower motoneurones in the spinal cord (Ono and Fukada, 1982; Bennett, Nathan, Wong et al., 1986).

Corticotropin-releasing factor. Corticotropin-releasing factor is known in the hypothalamus and also occurs in the spinal cord. Its location in the rat spinal cord has been studied by Merchenthaler, Hynes, Vigh, Shally, and Petruz (1983).

Vasoactive intestinal polypeptide (VIP). Vasoactive intestinal polypeptide usually referred to as VIP had been known previously in other tissue locations but was reported in 1976 in the brain and spinal cord (Larson, Fahrenkrug, Schaffalitsky et al., 1976). The distribution of this peptide in the spinal cord of mouse, rat, guinea pig, marmoset, cat, horse, and man has been studied (Gibson, Polak, Anand et al., 1984). In man, the main concentration of the peptide was found in two locations, both in the sacral segments of the spinal cord (Anand, Gibson, McGregor et al., 1983). VIP was prominent in these segments in the posterior horn in lamina I and in relation to the sacral parasympathetic neurones in the anterior horn.

Peptide histidine isoleucine (PHI). Peptide histidine isoleucine known as an intestinal peptide in the pig, was subsequently found in the brain and spinal cord (Tatemoto and Mutt, 1981; Tatemoto, Carlquist, McDonald and Mutt, 1983). PHI is found together with VIP in many tissues and the two peptides occur together in the posterior horn, where their concentration is simultaneously increased following section of the incoming fibres in the posterior nerve root. Further observations are needed on other spinal cord areas to determine its distribution, and its interdependence with VIP.

Neuropeptide $Y$ (NPY). Neuropeptide $Y$ was isolated from the brain of the pig (Tatemoto, 1982), and subsequently demonstrated in the human spinal cord (Allen, Gibson, Adrian et al., 1984). It is abundant throughout the body where it functions as a potent vasoconstrictor. In perfusion experiments it reduces the strength of myocardial contraction and the amount of cardiac blood flow. It is abundant in the human spinal cord, probably associated with noradrenergic neurones. 
C-flanking peptide of neuropeptide $\mathrm{Y}(\mathrm{C}-\mathrm{PON})$. This peptide, C-PON, may occur with neuropeptide $\mathrm{Y}$ on the same precursor molecule and the two peptides are found together in many locations of the central nervous system. In the human spinal cord, we found this peptide demonstrating many small calibre fibres in laminae II and III of the posterior horn, and thicker fibres in lamina I and in Lissauer's tract. Some fibres were seen around the central canal and in the anterior horn. They were numerous around the neurones of Onuf's nucleus. Reactive fibres were also prominent in the autonomic nuclei, being observed in the sympathetic neurones of the thoracic cord and the parasympathetic neurones in the sacral cord.

Calcitonin gene-related peptide (CGRP). Calcitonin gene-related peptide was discovered by the theoretical deduction of its amino acid sequence by recombinant DNA technology, and the production of an antibody against a synthetic peptide (Amara et al., 1982; Rosenfeld et al., 1983). CGRP is distributed widely throughout the central nervous system and is likely to have many functions both motor and sensory. Gibson, Polak, Bloom et al. (1984) have studied the distribution of the peptide in the spinal cord of man and 8 other species. Nerve fibres and terminals reacting with their antibody were found at all levels of the spinal cord, concentrated in the posterior horn, and derived from afferents from neurone cell bodies in the posterior root ganglia. The peptide has been observed in white matter and in the anterior horn, suggesting a very widespread function for this interesting peptide. Its distribution can be studied by the release of the peptide when capsaicin is given (Franco-Cereceda, Henke, Lundberg et al., 1987).

\section{The new neuroanatomy of the spinal cord}

It is too early in this subject to describe anything approaching a complete anatomical mapping of the spinal cord, and we cannot even give an accurate picture of the 7 'classical' transmitters and the 10 'new' neuropeptides reviewed here. The purpose of this review is to describe the progress that has been made and to emphasise some of the achievements. It is customary to refer to the grey matter of the spinal cord in regions or laminae from $\mathrm{I}$ to $\mathrm{X}$ in roman numerals. In this simpler review, we shall describe the grey matter of the spinal cord under the headings of posterior horn, anterior horn, grey matter around the central canal, autonomic grey matter, and Clarke's column (nucleus dorsalis).

Posterior horn. The posterior horn has been found to be enormously rich in the diversity and amount of neurotransmitters, which are found in relation both to nerve fibres and to the various neurones of laminae I, II, and III. These neurones, particularly those in laminae I and II, vary in size, and are extraordinarily diverse in function, this diversity being the explanation of the marshalling of the afferent information arriving in the fibres entering via the posterior nerve roots. Substance $\mathrm{P}$, for example, is normally abundant here, is depleted following posterior rhizotomy, either in an experimental animal or after a neurosurgical rhizotomy in an appropriate human case, and is bilaterally absent in the interesting condition of congenital insensitivity to pain. Enkephalin is also found abundantly in laminae I and II but seems to be locally produced and derived from intrinsic neurones of the spinal cord. In the present state of our 
knowledge, the amount of data referring to the presence of neurotransmitters in the posterior horn still is at the stage of confusion, but succeeding observations are gradually explaining the anatomical dipositions of neurones, nerve fibres, and the relevant neurotransmitters.

Anterior horn. Neurotransmitters seem much less abundant in the anterior horn than in the posterior horn, and their function also is less clear. Acetylcholine and also possibly calcitonin gene related peptide are likely to be important neurotransmitters for motoneurones. Fibres reacting to antibodies for substance $\mathrm{P}$, enkephalin, somatostatin, and neuropeptide $\mathrm{Y}$ are also found but their function is not precisely known. These and other neuropeptides are particularly abundant around the neurones of the nucleus of Onuf, the pudental nucleus concerned with micturition.

Autonomic grey matter. The sympathetic neurones arising within the spinal cord have their cell bodies in the intermediolateral cell column of the thoracic and upper lumbar segments. Many neuropeptides are found in relation both to the nerve fibres connected to these neurones, and also to the cell bodies (see table 22.4 of Gibson and Polak, 1986, for details). The parasympathetic neurones are in the anterior horn of the sacral segments, and in relation to these neurones are found the neuropeptides enkephalin, somatostatin, and cholecystokinin/gastrin-like peptide. The last mentioned peptide (CGLP) is the only peptide found so far that seems to have a function in relation to sympathetic and parasympathetic neurones (Gibson and Polak, 1986).

Grey matter around the central canal. This small area, called lamina $\mathrm{X}$ and also the nearby posterior grey commissure are known to be concerned with pain sensation, the absence of which has long been associated with this area in, for example, the disease syringomyelia. The neuropeptides substance P, CGLP, CGRP, VIP are found here and seem to be related to fibres relaying afferent information from the posterior roots. Other neuropeptides such as enkephalin and substance $\mathrm{Y}$ are also found here but are probably arising within the spinal cord.

Clarke's column. (nucleus dorsalis) The neurones of this nucleus are the origin of the posterior spinocerebellar tracts. Their neuropeptide environment has not been extensively studied, but in one report (Pioro, Hughes and Cuello, 1984), immunoreactivity to substance $P$ was demonstrated.

\section{Conclusion}

The findings described in this review amply demonstrate the great expansion in our knowledge of the anatomy of the spinal cord, and how the new methods have frequently been applied successfully to the study of the anatomy of the human spinal cord. The 7 'classical' neurotransmitters: acetylcholine; noradrenaline; dopamine; serotonin; GABA; glycine; and glutamic acid are briefly described. Then from about 40 neuropeptides known to occur in the spinal cord, 10 (substance $P$, enkephalin, somatostatin, thyrotropin releasing hormone, corticotropin releasing hormone, vasoactive intestinal polypeptide, peptide histidine isoleucine, neuropeptide $\mathrm{Y}, \mathrm{C}$-flanking peptide of neuropeptide $\mathrm{Y}$, and calcitonin gene-related peptide) are described more fully with notes of their common location and abundance in the spinal cord. Finally the anatomy, pri- 
marily of the grey matter of the spinal cord is described in the light of these new observations. The amount of new data is immense but we are still at the beginning of an exciting world of new anatomical discovery, in which anatomy is linked to physiology by the finding in the spinal cord of these potent neurotransmitters, the distribution of which gives us 'The New Neuroanatomy of the Spinal Cord.'

\section{References}

Allen JM, Gibson SJ, Adrian T, et al. 1984 Neuropeptide Y in human spinal cord. Brain Research 308:145-148.

Amara SG, Jonas V, Rosenfeld MG, et al. 1982 Alternative RNA processing in calcitonin gene expression generates mRNAs encoding different polypeptide products. Nature 298:240-244

ANAND P, Gibson SJ, Yiangou Y, et al. PHI-like immunoreactivity co-locates with the VIPcontaining system in human lumbosacral spinal cord, Neuroscience Letters 46(1984):191-196.

Bennett GW, Nathan PA, Wong KK, et al. 1986 Regional distribution of immunoreactivethyrotrophin-releasing hormone and substance $\mathrm{P}$ and indoleamines in human spinal cord. Fournal of Neurochemistry 46:1718-1724.

BROWNSTEIN MJ 1977 Biological active peptides in the mammalian central nervous system. In: Peptides in Neurobiology. Plenum Press, New York and London.

Cuello AC, Kanazawa I 1978 The distribution of substance P immunoreactive fibres in the rat central nervous system. Fournal of Comparative Neurology 178:129-156.

Cuello CA, Polak JM, Pearse A 1976 Substance P: a naturally occurring transmitter in human spinal cord. Lancet ii:1054-1056.

Cuello AC, Priestley JV, Sofroniew MV 1983 Review article. Immunocytochemistry and Neurobiology. Quarterly fournal of Experimental Physiology 68:545-578.

ECCLes JC 1957 The Physiology of Nerve Cells. Johns Hopkins Press, Baltimore.

EULER US, vON GADDUM JH 1931 An unidentified depressor substance in certain tissue extracts, Fournal of Physiology 72:74-87.

Franco-Cereceda A, Henke H, Lundberg JM, et al. 1987 Calcitonin gene-related peptide (CGRP) in capsaicin-sensitive substance P-immunoreactive sensory neurons in animals and man: Distribution and release by capsaicin. Peptides 8:399-410.

Hunt SP, Rossor NM, Emson PC, et al. 1982 Substance P and enkephalins in spinal cord after limb amputation. Lancet $\mathbf{i}: 1023$.

Gibson SJ, Polak JM, Bloom SR, et al. Calcitonin gene-related peptide immunoreactivity in the spinal cord of man and of eight other species. Fournal of Neuroscience 4:3101-3111.

Gibson SJ, Polak JM, ANANd P, et al. 1984 The distribution and origin of VIP in the spinal cord of six mammalian species. Peptides 5:201-207.

Gibson SJ, Polak JM, Katagiri T, et al. 1988 A comparison of the distribution of eight peptides in spinal cord from normal controls and cases of motor neurone disease with special reference to Onuf's nucleus (In preparation).

HUGHES J 1975 Isolation of an endogenous compound from the brain with pharmacological properties similar to morphine. Brain Research 88:295-308.

Hughes J, SMith TW, Kosterlitz HW, et al. 1975 Identification of two related pentapeptides from the brain with potent opiate agonist activity. Nature 258:577-579.

Hughes J, Kosterlitz HW, SMITH TW 1977 The distribution of methionine-enkephalin and leucine-enkephalin in the brain and peripheral tissues. British fournal of Pharmacology 61:639647.

Hunt SP, Rossor MN, Emson PC, et al. 1982 Substance P and enkephalins in spinal cord after limb amputation, Lancet i:1023.

KoHLER G, Milstein C 1975 Continuous cultures of fused cells secreting antibody of predefined specificity. Nature 256:495-497.

La MotTe CC, De LANerolle NC 1981 Human spinal neurons: innervation by both substance $P$ and enkephalins. Neuroscience 6:713-723.

Larsson Li, Fahrenkrug J, Schaffalitzky De MuCKadell OB, et al. 1976 Localisation of vasoactive intestinal polypeptide (VIP) to central and peripheral neurons. Proceedings of the National Acadamy of Sciences of the USA 78:3197-3200.

MERChenthaler I, HyNES MA, Vigh S, et al. 1983 Immunocytochemical localisation of corticotrophin releasing factor (CRF) in the rat spinal cord. Brain Research 275:373-377.

ONO H, FUKADA H 1982 Ventral root depolarisation and spinal reflex augmentation by a TRH analog in rat spinal cord. Neuropharmacology 21:39-44. 
Pearson J, Brandeis L, Cuello AC 1982 Depletion of substance P-containing axons in the substantia gelantinosa of patients with diminished pain sensitivity. Nature 295:61-63.

Pioro EP, Hughes JT, Cuello AC 1984 Loss of substance P and enkephalin immunoreactivity in the human substantia nigra after striato-pallidal infarction. Brain Research 292:339-347.

RAMON Y CAJAL S 1899-1904 Textura del sistema nervioso del hombre y de los vertebrados. Nicolas Moya, Madrid.

RAMON y CAJAL S 1952 Histologie du systeme nerveux de l'homme et ses vertebres, Vols 1 and 2. Instituto Ramon y Cajal, Madrid.

RAMON Y CAJAL S 1959 Degeneration and Regeneration in the Nervous System. Hafner, New York.

Rosenfeld MG, Mermod JJ, Amara SG, et al. 1983 Production of a novel neuropeptide encoded by the CT gene via tissue-specific RNA processing. Nature 304:129-135.

Schoenen J, Lotstra F, Vierendeels G, et al. 1985 Substance P, enkephalins, somatostatin, cholecystokinin, oxytocin and vasopressin in human spinal cord. Neurology 35:881-890.

SCHRODER HD 1984 Somatostatin in the caudal spinal cord: An immunohistochemical study of the spinal centres involved in the innervation of pelvic organs. Fournal of Comparative Neurology 223:400-414.

SHERRINGTON CS 1906 The Integrative Action of the Nervous System. Yale UP, New Haven.

Tатемото K 1982 Neuropeptide Y: complete aminoacid sequence of the brain peptide. Proceedings of the National Academy of Sciences of the USA 79:5485-5489.

Tатемото K, Mutt V 1981 Isolation and characterisation of the intestinal peptide porcine PHI (PHI-27) a new-member of the glucagon-secretin family. Proceedings of the National Academy of Sciences of the USA 78:6603-6607.

TATEMoto KM, CARLQUist TJ, MCDonald TJ, et al. 1983 Isolation of a brain peptide identical to the intestinal PHI (peptide HI). FEBS Letters 153:248-252. 